\title{
Perspectives on treatment advances for stage III locally advanced unresectable non-small-cell lung cancer
}

\author{
P.K. Cheema MD MBiotech, ${ }^{*}$ J. Rothenstein $\mathrm{MD}^{\dagger}{ }^{\dagger}$ B. Melosky $\mathrm{MD}^{\ddagger}{ }^{\ddagger}$ A. Brade $\mathrm{MD}^{\S}$ and V. Hirsh $\mathrm{MD}^{\|}$
}

\begin{abstract}
For more than a decade, there has been no improvement in outcomes for patients with unresectable locally advanced (LA) non-small-cell lung cancer (NSCLC). The standard treatment in that setting is definitive concurrent chemotherapy and radiation (CCRT). Although the intent of treatment is curative, most patients rapidly progress, and their prognosis is poor, with a 5 -year overall survival (os) rate in the $15 \%-25 \%$ range. Those patients therefore represent a critical unmet need, warranting expedited approval of, and access to, new treatments that can improve outcomes. The PACIFIC trial, which evaluated durvalumab consolidation therapy after CCRT in unresectable LA NSCLC, demonstrated a statistically significant and clinically meaningful improvement in progression-free survival (PFS) and a significant improvement in os. Durvalumab thus fills a critical unmet need in the setting of unresectable LA NSCLC and provides a new option for patients treated with curative intent. Here, we review the treatment of unresectable LA NSCLC, with a focus on the effect of the clinical data for durvalumab.
\end{abstract}

Key Words Lung cancer, stage III disease, immunotherapy

Curr Oncol. 2019 Feb;26(1):37-42

www.current-oncology.com

\section{INTRODUCTION}

Lung cancer remains the leading cause of cancer-related death in Canada, carrying a morbidity rate higher than the rate for the other three major-incidence cancer types (breast, colon, and prostate) combined ${ }^{1}$. Lung cancer represents $14 \%$ of new cancers overall, with an estimated 28,400 cases diagnosed in Canada in 2016. Non-small-cell lung cancer (NSCLC) constitutes more than $80 \%$ of all lung tumours and can be further subdivided into adenocarcinoma, squamous cell carcinoma, and large-cell carcinoma, representing $35 \%-40 \%, 25 \%-30 \%$, and $10 \%-15 \%$ of all lung cancers respectively ${ }^{2,3}$.

Staging of NSCLC uses the TNM system, which describes the size and extent of the primary tumour, the number and location of involved regional lymph nodes, and the presence and location of any metastatic disease ${ }^{4}$. Most patients with NSCLC are diagnosed with locally advanced or metastatic disease ${ }^{5}$. Broadly, stage III [locally advanced (LA)] NSCLC encompasses a heterogeneous group of tumour presentations defined as having spread locoregionally through primary tumour extension into extrapulmonary structures (T3/4) and involving hilar or mediastinal lymph nodes (N1-3), but having no evidence of distant metastases (M0). Effective January 2018, to further improve prognostication and to guide appropriate current management, the latest revisions within the 8th edition of the TNM cancer staging classification published by the American Joint Committee on Cancer were derived using data analysis from the International Association for the Study of Lung Cancer ${ }^{6}$.

Although the $20 \%-30 \%$ of patients who present with stage III NSCLC have, by definition, disease that is confined to the thorax, surgery as the primary modality for curative treatment is rarely feasible, other than in select patients in this grouping (for example, T3N1M0 and T4NOM0), and has not been shown to be superior to definitive concurrent chemotherapy and radiation (CCRT) ${ }^{7}$.

\section{PERSPECTIVES}

\section{Current Management of Unresectable LA NSCLC}

For more than two decades, the standard treatment for unresectable LA NSCLC has been thoracic radiotherapy $(\mathrm{RT})^{8,9}$. Although improvements in radiation delivery such as 3-dimensional conformal RT have made treatment safer and less toxic, the current standard of care for these 
patients is radiation with concurrent platinum-based chemotherapy. The recommendation to add chemotherapy to RT is based on studies showing an improved os for that regimen compared with RT only, with a meta-analysis demonstrating an absolute benefit of $2.2 \%$ at 5 years [hazard ratio (HR): 0.89; 95\% confidence interval (CI): 0.81 to $0.98 ; p=0.02]^{10,11}$. Furthermore, chemotherapy given concurrently is preferred to sequential treatment, given the significant os benefit of $4.5 \%$ at 5 years (HR: $0.84 ; 95 \%$ CI: 0.74 to $0.95 ; p=0.004)^{8}$.

The optimal concurrent chemotherapy regimen has not been determined. Commonly used regimens include cisplatin-etoposide and weekly low-dose carboplatinpaclitaxel ${ }^{12,13}$. More recent phase III studies (PROCLAIM and RTOG 0617) demonstrated that neither the addition of the multi-targeted antifolate agent, pemetrexed, nor the anti-EGFR antibody, cetuximab, to platinum-based CCRT improved survival ${ }^{14,15}$. Similarly, increasing the dose of radiation to $74 \mathrm{~Gy}$ from the standard $60 \mathrm{~Gy}$ was not associated with an os benefit; in fact, the standard treatment arm was shown to be superior, with a median os of 28.7 months for patients receiving standard-dose RT and 20.3 months for those receiving high-dose RT (HR: 1.38; 95\% CI: 1.08 to $1.76 ; p=0.004)^{15}$. The use of consolidation chemotherapy also proved to be ineffective at improving outcomes and is not currently recommended after standard-dose CCRT ${ }^{12}$.

\section{Unmet Need in Unresectable LA NSCLC}

Although the intent of CCRT is curative, most patients will relapse, with nearly $40 \%$ experiencing locoregional recurrence, and approximately $50 \%$ or more developing distant metastasis ${ }^{14,15}$. Moreover, median PFs is short at 8-12 months, and the 5-year os rates remain low at $15 \%-25 \%^{7,8}$. Over time, those values have remained relatively unchanged, as evidenced by the median PFs of 11.4 months reported in the earlier-mentioned PROCLAIM study and 11.8 months in RTOG $0617^{14,15}$. Given the high risk of metastasis and a short PFs after CCRT, one strategy aimed at improving outcomes is consolidation therapy, defined as treatment administered after the end of a defined number of chemotherapy cycles with or without RT, in a patient whose tumour has been controlled ${ }^{16}$. However, to date, no phase III studies of consolidation with chemotherapy, targeted therapy, or vaccines have demonstrated a PFs or os benefit in patients with unresectable LA NSCLC (Table I).

\section{Consolidation Therapy in Unresectable LA NSCLC}

Six randomized phase IIB/III trials examined consolidation therapy with chemotherapy, targeted therapies, or vaccines after CCRT in advanced unresectable LA NSCLC, all of which did not improve patient outcomes (Table I). Studies using chemotherapy included the use of docetaxel monotherapy, cisplatin-docetaxel, or cisplatin-vinorelbine ${ }^{17,20,22}$.

The swog S0023 study examined gefitinib after CCRT and docetaxel consolidation, given until progression or unacceptable toxicity, for up to 5 years $^{18}$. Despite a reasonable safety profile, os was significantly lower in the gefitinib arm. Furthermore, two studies examined the use of vaccine therapies as consolidation in this setting: the START trial of tecemotide (LBLP25) compared with placebo and the sTop trial of belagenpumatucel-L compared with placebo, both of which failed to show statistical improvements in os ${ }^{19,21}$. Finally, a pooled analysis of forty-two studies comparing consolidation chemotherapy after CCRT with best supportive care showed no difference in median os $(p=0.4)^{25}$.

\section{Checkpoint Inhibitors in NSCLC}

Despite the lack of new therapies in unresectable LA NSCLC, the years since about 2010 have brought vast gains in the understanding of the molecular mechanisms associated with tumour immunology-notably, the role of immune synapse ("immune checkpoints") in the suppression of the antitumour immune response ("T cell exhaustion") ${ }^{26}$. Activation of $\mathrm{T}$ cells depends on engagement of the antigen receptor with antigen-presenting cells, and the costimulatory and co-inhibitory interactions of CD80/CD28 and PD-1/PD-L1 between cells. Evasion of the immune system by tumour cells occurs through a variety of mechanisms, including overexpression of certain ligands such as PD-L1 ${ }^{27}$. Discovery of those mechanisms has led to the development of several novel agents, including immune checkpoint inhibitors (ICIs) that specifically target PD-1, PD-L1, and the CTLA- 4 receptor, and agents that target other areas of the immune system pathway.

The PD-1/PD-Ll inhibitors block the interactions between PD-L1 on tumour cells and PD-1 on immune cells, thereby allowing the immune system to recognize and attack tumour cells ${ }^{28}$. The Icis have demonstrated efficacy as a palliative treatment for advanced incurable NSCLC. Nivolumab, pembrolizumab, and atezolizumab are PD-1/ PD-L1 inhibitors that, compared with docetaxel, have all improved os when given as monotherapy in metastatic NSCLC after platinum-containing chemotherapy ${ }^{29-31}$. In the case of pembrolizumab, a comparison with platinumbased doublet therapy in treatment-naïve patients showed improved os for those whose tumours had high PD-L1 expression (defined as a tumour proportion score $\geq 50 \%)^{32}$. Considering the broader prospective benefit of those effective inhibitor therapies, subsets of patients with metastatic disease, albeit in small numbers, have been shown to experience significant responses, resulting in prolonged disease-free survival. Thus, PD-1/PD-L1 inhibitors would be ideal therapies to move up into curative treatment regimens for earlier-stage NSCLC.

Theuse of IcIs as consolidation therapywithin a curativeintent management plan for LA NSCLC represents a promising strategy to improve outcomes after CCRT. In NSCLC, the antitumour immunogenic effects of radiation might act as an adjuvant to checkpoint blockade. Theoretically, the combination of RT and ICIs could lead to enhanced responses by increasing the exposure or altering the presentation of tumour-related antigens to immune system cells. In a study of patients with advanced NSCLC treated with pembrolizumab, PFS and os were longer in those who had previously received $\mathrm{RT}$ than in those who had not $\mathrm{t}^{33}$. Also, compared with patients who received pembrolizumab alone, patients who were randomized to receive stereotactic body radiation therapy for a single metastasis before receiving pembrolizumab for advanced NSCLC experienced an improved response rate ( $41 \%$ vs. $19 \%)$ and PFS (6.4 months vs. 1.8 months; HR: $0.55 ; p=0.04)^{34}$. 
TABLE I Randomized phase IIB/III studies examining maintenance or consolidation therapy after chemoradiation for unresectable stage III nonsmall-cell lung cancer

\begin{tabular}{|c|c|c|c|c|}
\hline \multirow[t]{2}{*}{ Study } & \multirow[t]{2}{*}{ Treatment groups } & \multicolumn{2}{|c|}{ Survival (months) } & \multirow[t]{2}{*}{ Safety } \\
\hline & & Progression-free & Overall & \\
\hline Hanna et al., $2008^{17}$ & $\begin{array}{c}\text { Docetaxel }\left(75 \mathrm{mg} / \mathrm{m}^{2}\right) \\
\text { every } 3 \text { weeks for } 3 \text { cycles } \\
\text { vs. } \\
\text { observation }\end{array}$ & $\begin{array}{l}\text { Nonsignificant } \\
\qquad(p=0.960)\end{array}$ & $\begin{array}{c}21.2 \\
\text { vs. } \\
23.2 \\
(p=0.883)\end{array}$ & $\begin{array}{l}\text { Higher rates of pneumonitis }(9.6 \% \text { vs. } \\
1.4 \%, p<0.001) \text { and infection }(11.0 \% \text { vs. } \\
0 \%, p=0.003)\end{array}$ \\
\hline $\begin{array}{l}\text { Kelly et al., } 2008^{18} \\
\text { (SWOG S0023) }\end{array}$ & $\begin{array}{l}\text { Gefitinib ( } 250 \text { mg daily) } \\
\text { up to } 5 \text { years } \\
\text { vs. } \\
\text { observation }\end{array}$ & $\begin{array}{c}8.3 \\
\text { vs. } \\
11.7 \\
(p=0.17)\end{array}$ & $\begin{array}{l}23 \\
\text { vs. } \\
35 \\
(p=0.013)\end{array}$ & Toxicity-related deaths: $2 \%$ vs. $0 \%$ \\
\hline $\begin{array}{l}\text { Butts et al., } 2014^{19} \\
\text { (START) }\end{array}$ & $\begin{array}{c}\text { Tecemotide }(806 \mu \mathrm{g}) \\
\text { every } 6 \text { weeks until progression } \\
\text { vs. } \\
\text { placebo }\end{array}$ & $\begin{array}{c}10.0 \\
\text { vs. } \\
8.4 \\
(p=0.053)\end{array}$ & $\begin{array}{c}25.6 \\
\text { vs. } \\
22.3 \\
(p=0.123)\end{array}$ & $\begin{array}{l}\text { Grade } 3 / 4 \text { adverse events not greater with } \\
\text { tecemotide: } \\
\quad \text { Dyspnea, } 5 \% \text { vs. } 4 \% \\
\text { Pneumonia, } 2 \% \text { vs. } 3 \% \\
\text { Serious immune-related adverse events } \\
\text { also did not differ }\end{array}$ \\
\hline Ahn et al., $2015^{20}$ & $\begin{array}{c}\text { Docetaxel-cisplatin } \\
\left(35 \mathrm{mg} / \mathrm{m}^{2} \text { and } 35 \mathrm{mg} / \mathrm{m}^{2}\right) \\
\text { every } 3 \text { weeks for } 3 \text { cycles } \\
\text { vs. } \\
\text { best standard of care }\end{array}$ & $\begin{array}{c}8.1 \\
\text { vs. } \\
9.1 \\
(p=0.36)\end{array}$ & $\begin{array}{c}20.6 \\
\text { vs. } \\
21.8 \\
(p=0.44)\end{array}$ & $\begin{array}{l}\text { Higher rates of all-grade neutropenia } \\
(14.4 \% \text { vs. } 5.8 \%) \text {, esophagitis ( } 35.3 \% \text { vs. } \\
26.9 \%) \\
\text { Treatment-related mortality: } 3.6 \% \text { vs. } 0 \%\end{array}$ \\
\hline $\begin{array}{l}\text { Giaccone et al., } 2015^{21} \\
\text { (STOP) }\end{array}$ & $\begin{array}{c}\text { Belagenpumatucel-L } \\
\left(2.5 \times 10^{7} \text { cells per dose }\right) \\
\text { for } 20 \text { cycles } \\
\text { vs. } \\
\text { placebo }\end{array}$ & 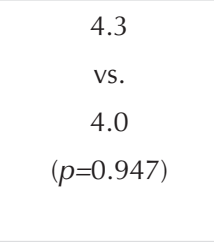 & $\begin{array}{c}20.3 \\
\text { vs. } \\
17.8 \\
(p=0.594)\end{array}$ & $\begin{array}{l}\text { Grade } 1 / 2 \text { erythema: } 35 \text { vs. } 7 \text { events } \\
(p<0.001) \\
\text { Injection site reactions: } 260 \text { vs. } 62 \text { events } \\
(p<0.001)\end{array}$ \\
\hline $\begin{array}{l}\text { Flentke et al., } 2016^{22} \\
\text { (GILT) }\end{array}$ & $\begin{array}{l}\text { Oral vinorelbine-cisplatin } \\
\left(60-80 \mathrm{mg} / \mathrm{m}^{2}, \text { days } 1 \text { and } 8,\right. \\
\left.\text { and } 80 \mathrm{mg} / \mathrm{m}^{2}, \text { day } 1\right) \\
\text { for } 2 \text { cycles } \\
\text { vs. } \\
\text { best standard of care }\end{array}$ & $\begin{array}{c}6.4 \\
\text { vs. } \\
5.5 \\
(p=0.63)\end{array}$ & $\begin{array}{c}20.8 \\
\text { vs. } \\
18.5 \\
(p=0.87)\end{array}$ & $\begin{array}{l}\text { Grade } 3 / 4 \text { adverse events: } \\
\begin{array}{l}\text { Neutropenia, } 10 \%-12 \% \text { vs. } 0 \% \\
\text { Leucopenia, } 5.8 \%-21 \% \text { vs. } 0 \% \\
\text { Fatigue, } 3.5 \% \text { vs. } 0 \% \\
\text { Nausea, } 2.3 \% \text { vs. } 0 \%\end{array}\end{array}$ \\
\hline $\begin{array}{l}\text { Antonia et al., } 2017^{23,24} \\
\quad \text { (PACIFIC) }\end{array}$ & $\begin{array}{c}\text { Durvalumab }(10 \mathrm{mg} / \mathrm{kg}) \\
\text { every } 2 \text { weeks for } 1 \text { year } \\
\text { vs. } \\
\text { placebo }\end{array}$ & $\begin{array}{c}17.2 \\
\text { vs. } \\
5.6 \\
(\text { HR: } 0.51 ; \\
p<0.001)\end{array}$ & $\begin{array}{c}\text { NR } \\
\text { vs. } \\
28.7 \\
(\text { HR: } 0.68 ; \\
p=0.0025)\end{array}$ & $\begin{array}{l}\text { - } \quad \text { Pneumonitis: } 34 \% \text { vs. } 29 \% \\
\text { - Grade } 3 / 4 \text { pneumonitis: } 4 \% \text { vs. } 4 \% \\
\text { - Grade } 3 / 4 \text { immune-related adverse events: } \\
3.4 \% \text { vs. } 2.6 \%\end{array}$ \\
\hline
\end{tabular}

$\mathrm{HR}=$ hazard ratio; $\mathrm{NR}=$ not reached.

\section{Durvalumab for the Treatment of Unresectable LA NSCLC}

Durvalumab is a fully human monoclonal antibody directed against PD-Ll that blocks binding to its receptors (PD-1 and CD80), eliciting enhanced T cell activity against tumour cells ${ }^{23}$. Recently, based on results of the PACIFIC study, and after priority review and breakthrough therapy designations had been awarded, both the U.S. Food and Drug Administration and Health Canada approved durvalumab for patients with unresectable stage III LA NSCLC who have not progressed after CCRT ${ }^{35,36}$.

The PACIFIC trial was a randomized phase III doubleblind placebo-controlled multicentre trial that compared durvalumab for 12 months with placebo in patients with unresectable stage III NSCLC who were without disease progression after CCRT with platinum-based chemotherapy ${ }^{23}$. Patients were enrolled within 6 weeks of completing CCRT. As a point of reference, the PACIFIC trial began when the 7th 
edition of American Joint Committee on Cancer TNM staging system was in effect; however, patients within the 8th edition's stage III categories, including stage IIIC, fit within the PACIFIC trial's disease specification criteria. That global study enrolled 713 patients at 234 participating centres, 21 of which were Canadian.

Durvalumab was associated with a statistically significant and clinically meaningful improvement in survival at 2 years, with an absolute difference of $10.7 \%$ in the durvalumab arm $(66.3 \%$; $95 \%$ CI: $61.7 \%$ to $70.4 \%)$ compared with the placebo arm (55.6\%; 95\% CI: 48.9 to $61.8 ; p=0.005)$. At a median follow-up of 25.2 months, the median os had not been reached with durvalumab and was 28.7 months with placebo (HR: $0.68 ; p=0.0025)^{24}$. The second primary endpoint of PFs assessed by blinded independent central review was also significantly improved with durvalumab (17.2 months vs. 5.6 months; HR: $0.51 ; p<0.001)$. The os and PFs benefits were seen in all prespecified subgroups, including histology, smoking history, stage, and level of PD-Ll expression (defined as high vs. low or negative). An exploratory post hoc analysis of os in patients with different levels of PD-L1 expression (on the basis of archived tumour samples obtained before CCRT), found that, of the $63 \%$ of patients with evaluable PD-L1 measurements, patients with tumours that were PD-L1-negative might not have benefited from durvalumab (HR: 1.36; 95\% CI: 0.79 to $2.34)$. Secondary endpoints of overall response $(30.0 \%$ vs. $17.8 \%, p<0.001$ ) and time to distant metastasis or death (28.3 months vs. 16.2 months; HR: $0.53 ; p<0.0001$ ) were significantly improved with durvalumab, with no detriment to quality of life.

Limitations of the study included a lower-thanexpected median PFs in the control arm (5.6 months compared with historical controls of 8-12 months). However, prior trials involving consolidation treatment after CCRT included different patient populations, had varying induction or consolidation treatment designs, and used different doses of chemotherapy and radiation. Values therefore cannot effectively be directly compared. Furthermore, PFS was often collected from the time patients started their CCRT; in contrast, the PACFIC trial began its assessment of patients at their first day of randomization to the treatment arms after completion of CCRT. More importantly, survival in the control arm was as expected or slightly better than historical controls from recent studies (for example, the median os of 25.6 months in the sTART study, which randomized patients after CCRT) ${ }^{19}$. A criticism of the study design is that positron-emission tomography imaging and brain magnetic resonance imaging were not mandated, and no information about rates of positron-emission tomography imaging or magnetic resonance imaging has been provided. Thus, it is possible that patients with occult brain metastases or distant metastases were inadvertently included in the study.

A concern about initiating an anti-PD-1/PD-L1 monoclonal antibody shortly after a definitive dose of radiation has been delivered to the chest is the theoretical combined risk of pneumonitis. That adverse event is a recognized complication of both RT (radiation pneumonitis) and ICIS (autoimmune-related pneumonitis). Despite the rate of all-grade pneumonitis being higher with durvalumab than with placebo $(33.9 \%$ vs. $24.8 \%)$, rates of grades $3-5$ pneumonitis were low in both arms, and no meaningful difference was observed $(4.4 \% \text { vs. } 4.3 \%)^{23}$. Overall, postCCRT treatment with durvalumab was well tolerated. The safety profile was consistent with and within the expectations demonstrated in earlier studies with durvalumab and trials of other anti-PD-1/PD-L1 monotherapies in NSCLC.

Other ICIs are currently under investigation for patients with unresectable LA NSCLC. A single-arm phase II study of pembrolizumab given as consolidation after CCRT enrolled 92 patients and demonstrated a PFs of 17 months, similar to that seen with durvalumab, with a rate of grades $3-5$ pneumonitis of $6.5 \%^{38}$, providing further support for the effectiveness and safety of anti-PD-1/PD-L1 antibodies in improving outcomes for patients with unresectable LA NSCLC.

\section{Remaining Questions}

The addition of durvalumab consolidation was associated with a clinically meaningful delay in the development of incurable or stage IV NSCLC - a state associated with a high symptom burden and reduced quality of life. However, the aim of any novel therapy approach for patients with LA NSCLC is to improve cure rates. With early follow-up, it is suggestive that durvalumab might in fact improve cure rates in unresectable LA NSCLC, with an improved 2-year os; however, an improvement in 5-year os has generally been accepted as the likelihood of cure.

As a contemporary benchmark to quantify newly discovered improvements, the addition of postoperative adjuvant chemotherapy for early-stage NSCLC improved cure rates by $5 \%$, which led to its widely accepted use ${ }^{39}$. Interestingly, the os curves with durvalumab seem to be widening with time, with an absolute improvement at 1 year of $7.8 \%$ and $10.7 \%$ at 2 years. Thus, durvalumab therapy will quite possibly reach the benchmark of improvement in survival set by prior practice-changing studies in early-stage NSCLC. However, with the cost of durvalumab for infusion being CA $\$ 7.82$ per milligram $(10 \mathrm{mg} / \mathrm{kg}$ for a $70 \mathrm{~kg}$ patient, thus costing CA $\$ 5,474)$, the survival threshold that would be required for durvalumab to be cost-effective is uncertain. Its use will certainly require an increase in resources for cancer clinics whose patients with LA NSCLC will require infusion visits every 2 weeks for 1 year. Also, the safety and efficacy of durvalumab are unknown for populations that were not included in the PACIFIC trial: patients with multiple comorbidities or poor lung function, patients with decreased performance status after CCRT, patients who require recovery beyond 6 weeks after completion of CCRT, and patients who received sequential chemoradiation rather than CCRT. Finally, the post hoc analysis suggesting a lack of benefit with durvalumab in patients with PD-L1negative tumours warrants further investigation. Until definitive data become available, a different approach for those patients is likely unjustified, although a discussion with members of that patient population about the uncertainty could be appropriate.

Patients with stage III NSCLC constitute a heterogeneous population. Decision-making for those patients often requires the cumulative perspectives of surgeons, radiation oncologists, and medical oncologists. No single definition 
of "unresectable" at this stage of NSCLC is universally accepted; the patients determined to be unresectable can vary between institutions for a number of reasons $s^{9,40,41}$. Generally, resectability is determined case by case by an experienced thoracic surgeon in a multidisciplinary team environment. In LA disease, surgery after CCRT could be an option for a select group of patients; it is also possible that resectability status could change after CCRT ${ }^{7,42}$. Durvalumab has not been studied in such patients who receive trimodality therapy, and it is therefore unknown whether patients who undergo resection after CCRT should also be offered durvalumab as a component of their curative treatment plan. It is similarly unknown whether patients who carry a relatively high surgical risk or have an uncertain resectability status would achieve greater benefit by forgoing surgery and receiving durvalumab after CCRT. Finally, further research to optimize the use of ICIS in LA NSCLC, in terms of timing and length of therapy, is required. One such study is the NICHOLAs trial, which is evaluating the use of ICIs given earlier in treatment by giving nivolumab concurrent with chemotherapy and radiation (see NCT02434081 at http://ClinicalTrials.gov/).

\section{SUMMARY}

Patients with unresectable stage III NSCLC have a poor prognosis despite curative-intent therapy with CCRT. For more than a decade, no improvements in patient outcomes or management have been achieved in that setting, although a small fraction of that patient population survives past 5 years. The ICIs appear to be a promising addition to treatment for LA NSCLC, with durvalumab consolidation after CCRT representing a major therapeutic advance. Durvalumab fills an unmet need for patients with unresectable and yet potentially curable NSCLC, for which effective therapies beyond concurrent platinum-based CCRT have been critically lacking. If cost-effectiveness is favourable with durvalumab, then the use of health care resources to support its use in this patient population would be warranted.

\section{ACKNOWLEDGMENTS}

The authors thank Anna Christofides of IMPACT Medicom Inc., who contributed to the development of this paper by providing medical writing assistance.

\section{CONFLICT OF INTEREST DISCLOSURES}

We have read and understood Current Oncology's policy on disclosing conflicts of interest, and we declare the following interests: PKC reports attending advisory boards and receiving honoraria from AstraZeneca, Boehringer Ingelheim, Bristol-Myers Squibb, Merck, Novartis, Pfizer, Roche, and Takeda, all of which were outside of the submitted work; JR reports attending advisory boards and receiving honoraria from AstraZeneca, Bristol-Myers Squibb, Merck, Pfizer, and Hoffmann-La Roche, all of which were outside the submitted work; PKC and JR were also investigators in the PACIFIC clinical trial; BM reports attending advisory boards and receiving honoraria from AstraZeneca, Merck, Bristol-Myers Squibb, Boehringer Ingelheim, Novartis, and Pfizer, all of which were outside the submitted work; $A B$ reports travel support to a conference from Eli Lilly and attending an advisory board for AstraZeneca, both of which were outside the submitted work; $\mathrm{VH}$ reports attending advisory boards and receiving honoraria from AstraZeneca, Boehringer Ingelheim, Bristol-Myers Squibb,
Merck, Pfizer, Hoffmann-La Roche, and AbbVie, all which were outside the submitted work.

\section{AUTHOR AFFILIATIONS}

*William Osler Health System, Brampton/Toronto, and University of Toronto, Toronto, ON; ${ }^{\dagger}$ R.S. McLaughlin Durham Regional Cancer Centre, Oshawa, and Queen's University, Kingston, ON; ${ }^{\ddagger} \mathrm{BC}$ Cancer-Vancouver and University of British Columbia, Vancouver, BC; ${ }^{\circledR}$ Peel Regional Cancer Centre, Mississauga, and University of Toronto, Toronto, ON; "Royal Victoria Hospital and McGill University, Montreal, QC.

\section{REFERENCES}

1. Canadian Cancer Society's Advisory Committee on Cancer Statistics. Canadian Cancer Statistics 2016. Toronto, ON: Canadian Cancer Society; 2016.

2. Crino L, Weder W, van Meerbeeck J, Felip E on behalf of the ESMo Guidelines Working Group. Early stage and locally advanced (non-metastatic) non-small-cell lung cancer: ESMO clinical practice guidelines for diagnosis, treatment and follow-up. Ann Oncol 2010;21(suppl 5):v103-15.

3. International Agency for Research on Cancer (IARC). GLOBOCAN 2012: Estimated Cancer Incidence, Mortality and Prevalence Worldwide in 2012. Lyon, France: IARC; 2012.

4. Rami-Porta R, Bolejack V, Crowley J, et al. on behalf of the IASLC Staging and Prognostic Factors Committee, Advisory Boards and Participating Institutions. The IAscL Lung Cancer Staging Project. Proposals for the revisions of the $\mathrm{T}$ descriptors in the forthcoming eighth edition of the TMN classification of lung cancer.J Thorac Oncol 2015;10:990-1003.

5. Morgensztern D, Ng SH, Gao F, Govindan R. Trends in stage distribution for patients with non-small cell lung cancer: a National Cancer Database survey. J Thorac Oncol 2010;5:29-33.

6. American Joint Committee on Cancer (AJCC). Lung Cancer Staging. 8th ed. Chicago, IL: AJCC; 2009.

7. Albain KS, Swann RS, Rusch VW, et al. Radiotherapy plus chemotherapy with or without surgical resection for stage III non-small cell lung cancer: a phase III randomised controlled trial. Lancet 2009;374:379-86.

8. Auperin A, Le Pechoux C, Rolland E, et al. Meta-analysis of concomitant versus sequential radiochemotherapy in locally advanced non-small-cell lung cancer. J Clin Oncol 2010;28:2181-90.

9. National Comprehensive Cancer Network (NCCN). NCCN Clinical Practice Guidelines in Oncology: Non-Small Cell Lung Cancer. Ver. 9.2017. Fort Washington, PA: NCCN; 2017. [Current version available online at: https://www.nccn.org/ professionals/physician_gls/pdf/nscl.pdf (free registration required); cited 21 September 2018]

10. Chemotherapy in non-small cell lung cancer: a meta-analysis using updated data on individual patients from 52 randomised clinical trials. Non-small Cell Lung Cancer Collaborative Group. BMJ 1995;311:899-909.

11. Auperin A, Le Pechoux C, Pignon JP, et al. on behalf of MetaAnalysis of Cisplatin/Carboplatin Based Concomitant Chemotherapy in Non-Small Cell Lung Cancer group. Concomitant radio-chemotherapy based on platin compounds in patients with locally advanced non-small cell lung cancer (NSCLC): a meta-analysis of individual data from 1764 patients. Ann Oncol 2006;17:473-83.

12. Bezjak A, Temin S, Franklin G, et al. Definitive and adjuvant radiotherapy in locally advanced non-small-cell lung cancer: American Society of Clinical Oncology clinical practice guideline endorsement of the American Society for Radiation Oncology evidence-based clinical practice guideline. J Clin Oncol 2015;33:2100-5. 
13. Steuer CE, Behera M, Ernani V, etal. Comparison of concurrent use of thoracic radiation with either carboplatin-paclitaxel or cisplatin-etoposide for patients with stage III non-small-cell lung cancer: a systematic review. JAMA Oncol 2017;3:1120-9.

14. Senan S, Brade A, Wang LH, et al. Proclaim: randomized phase III trial of pemetrexed-cisplatin or etoposide-cisplatin plus thoracic radiation therapy followed by consolidation chemotherapy in locally advanced nonsquamous non-smallcell lung cancer. J Clin Oncol 2016;34:953-62.

15. Bradley JD, Paulus R, Komaki R, et al. Standard-dose versus high-dose conformal radiotherapy with concurrent and consolidation carboplatin plus paclitaxel with or without cetuximab for patients with stage IIIA or IIIB non-small-cell lung cancer (RTOG 0617): a randomised, two-by-two factorial phase 3 study. Lancet Oncol 2015;16:187-99.

16. Thatcher N, Heighway J. Maintenance and consolidation therapy in patients with unresectable stage III/IV non-small cell lung cancer. Oncologist 2010;15:1034-42.

17. Hanna N, Neubauer M, Yiannoutsos C, et al. on behalf of the Hoosier Oncology Group and U.S. Oncology. Phase III study of cisplatin, etoposide, and concurrent chest radiation with or without consolidation docetaxel in patients with inoperable stage III non-small-cell lung cancer: the Hoosier Oncology Group and U.S. Oncology. J Clin Oncol 2008;26:5755-60.

18. Kelly K, Chansky K, Gaspar LE, et al. Phase III trial of maintenance gefitinib or placebo after concurrent chemoradiotherapy and docetaxel consolidation in inoperable stage II non-smallcell lung cancer: swog S0023. JClin Oncol 2008;26:2450-6.

19. Butts C, Socinski MA, Mitchell PL, et al. Tecemotide (L-BLP25) versus placebo after chemoradiotherapy for stage III nonsmall-cell lung cancer (START): a randomised, double-blind, phase 3 trial. Lancet Oncol 2014;15:59-68.

20. Ahn JS, Ahn YC, Kim JH, et al. Multinational randomized phase III trial with or without consolidation chemotherapy using docetaxel and cisplatin after concurrent chemoradiation in inoperable stage III non-small-cell lung cancer: KCSG-LU05-04. J Clin Oncol 2015;33:2660-6.

21. Giaccone G, Bazhenova LA, Nemunaitis J, et al. A phase III study of belagenpumatucel-L, an allogeneic tumour cell vaccine, as maintenance therapy for non-small cell lung cancer. Eur J Cancer 2015;51:2321-9.

22. Flentje M, Huber RM, Engel-Riedel W, et al. GILT-a randomised phase III study of oral vinorelbine and cisplatin with concomitant radiotherapy followed by either consolidation therapy with oral vinorelbine and cisplatin or best supportive care alone in stage III non-small cell lung cancer. Strahlenther Onkol 2016;192:216-22.

23. Antonia SJ, Villegas A, Daniel D, et al. on behalf of the PACIFIC investigators. Durvalumab after chemoradiation in stage III non-small-cell lung cancer. N Engl J Med 2017;377;1919-29.

24. Antonia SJ, Villegas A, Daniel D, et al. on behalf of the PACIFIC investigators. Overall survival with durvalumab after chemoradiotherapy in stage III NSCLC. NEnglJMed 2018;:[Epub ahead of print].

25. Tsujino K, Kurata T, Yamamoto S, et al. Is consolidation chemotherapy after concurrent chemo-radiotherapybeneficial for patients with locally advanced non-small-cell lung cancer? A pooled analysis of the literature. J Thorac Oncol 2013;8:1181-9.

26. Kumar R, Collins D, Dolly S, McDonald F, O’Brien MER, Yap TA. Targeting the PD-1/PD-L1 axis in non-small cell lung cancer. Curr Probl Cancer 2017;41:111-24.

27. Tang C, Wang X, Soh H, et al. Combining radiation and immunotherapy: a new systemic therapy for solid tumors? Cancer Immunol Res 2014;2:831-8.

28. Granier C, De Guillebon E, Blanc, C et al. Mechanisms of action and rational use of immune checkpoint inhibitors in cancer. ESMO Open 2017;2:e000213.
29. Herbst RS, Baas P, Kim DW, et al. Pembrolizumab versus docetaxel for previously treated PD-L1 positive, advanced non-small-cell lung cancer (кеYNOTE 010): a randomised controlled trial. Lancet 2016;387:1540-50.

30. Borghaei H, Paz-Ares L, Horn L, et al. Nivolumab versus docetaxel in advanced nonsquamous non-small-cell lung cancer. N Engl J Med 2015;373:1627-39.

31. Rittmeyer A, Barlesi F, Waterkamp D, et al. Atezolizumab versus docetaxel in patients with previously treated non-smallcell lung cancer (OAK): a phase 3, open-label, multicentre randomised controlled trial. Lancet 2017;389:255-65.

32. Reck M, Rodríguez-Abreu D, Robinson AG, et al. on behalf of the KEYNOTE-024 investigators. Pembrolizumab versus chemotherapy for PD-L1-positive non-small-cell lung cancer. N Engl J Med 2016;375:1823-33.

33. Shaverdian N, Lisberg AE, Bornazyan K, et al. Previous radiotherapy and the clinical activity and toxicity of pembrolizumab in the treatment of non-small-cell lung cancer: a secondary analysis of the KEYNOTE-001 phase 1 trial. Lancet Oncol 2017;18:895-903.

34. Theelen W, Peulen H, Lalezari F, et al. Randomized phase II study of pembrolizumab after stereotactic body radiotherapy (SBRT) versus pembrolizumab alone in patients with advanced non-small cell lung cancer: the PEMBRo-RT study [abstract 9023].JClin Oncol 2018;36(suppl);. [Available online at: https://meetinglibrary.asco.org/record/160784/abstract; cited 12 October 2018]

35. United States, Department of Health and Human Services, Food and Drug Administration (FDA). FDA expands approval of Imfinzi to reduce the risk of non-small cell lung cancer progressing [online news release]. Silver Spring, MD: FDA; 2018. [Available at: https://www.fda.gov/newsevents/newsroom/ pressannouncements/ucm597217.htm; cited 27 August 2018]

36. AstraZeneca. First and only immuno-oncology treatment, Imfinzi (durvalumab), for stage III, unresectablenon-small cell lung cancer now approved in Canada [online news release]. Toronto, ON: Cision Canada; 2018. [Available at: https://www.newswire. ca/news-releases/first-and-only-immuno-oncology-treatmentimfinzi-durvalumab-for-stage-iii-unresectable-non-small-celllung-cancer-now-approved-in-canada-682157151.html; cited 27 August 2018]

37. Hui R, Ozguroglu M, Daniel D, et al. Patient-reported outcomes with durvalumab after chemoradiation in locally advanced, unresectable NscLC: data from PACIFIC. J Thorac Oncol 2017;12(suppl 2):S1604.

38. Durm GA, Althouse SK, Sadiq AA, et al. Phase II trial of concurrent chemoradiation with consolidation pembrolizumab in patients with unresectable stage III non-small cell lung cancer: Hoosier Cancer Research Network LUN 14-179 [abstract 8500]. J Clin Oncol 2018;36;. [Available online at: https://meetinglibrary.asco.org/record/160033/abstract; cited 12 October 2018]

39. Pignon JP, Tribodet H, Scagliotti GV, et al. on behalf of the LACE Collaborative Group. Lung Adjuvant Cisplatin Evaluation: a pooled analysis by the LACE Collaborative Group. J Clin Oncol 2008;26:3552-9.

40. Mery B, Guy JB, SwalduzA, et al. The evolving locally-advanced non-small cell lung cancer landscape: building on past evidence and experience. Crit Rev Oncol Hematol 2015;96:319-27.

41. Patel V, Shrager JB. Which patients with stage III non-small cell lung cancer should undergo surgical resection? Oncologist 2005; 10:335-44.

42. Cancer Care Ontario (cco). Non-small Cell Lung Cancer Treatment Pathway Map: Version 2017.11. Toronto, ON: cco; n.d. [Available online at: https://www.cancercareontario.ca/ sites/ccocancercare/files/assets/NSCLCTreatmentPathway Map_0.pdf; cited 23 July 2018] 